\title{
Single nucleotide polymorphisms in genes encoding xenobiotic metabolizing enzymes are associated with predisposition to arterial hypertension
}

\author{
Olga Yu. Bushueva \\ Kursk State Medical University, \\ 3 Karl Marx St., Kursk, 305041, Russia \\ Corresponding author: Olga Yu.Bushueva (olga.bushueva@inbox.ru)
}

\begin{abstract}
Background: Arterial hypertension (AH) is the most common disease of the cardiovascular system. Intracellular chemical and oxidative stress, which can be associated both with direct exposure to toxic xenobiotics and with their excessive activation during biotransformation, may lead to endothelial dysfunction and increased risk of AH development. The aim of the study: To investigate the association of single nucleotide polymorphisms of genes involved in the biotransformation of xenobiotics (rs1048943 CYP1A1, rs762551 CYP1A2, rs1056836 CYP1B1, rs1799930 NAT2, rs1800566 NQO1, rs11045642 MDRl) with predisposition to arterial hypertension. Materials and methods: A total of 702 patients with AH (307 men, 395 women; mean age 55 years) and 857 gender- and age- matched relatively healthy volunteers (406 men, 451 women; mean age 53 years) were recruited for the study. Genotyping of SNPs were done using TaqMan-based PCR. Results: Comparative analysis of genotype frequencies (logadditive regression model was used, all calculations were performed with adjustment for gender, age) showed that SNP rs762551 CYP1A2 was associated with a decreased risk of $\mathrm{AH}\left(\mathrm{OR}_{\mathrm{adj}}=0.85,95 \% \mathrm{CI}_{\mathrm{adj}}=0.73-0.99 ; \mathrm{P}_{\mathrm{adj}}=0.038\right)$; SNP rs1045642 MDRl (ABCB1) was associated with an increased risk of $\mathrm{AH}\left(\mathrm{OR}_{\mathrm{adj}}=1.20,95 \% \quad \mathrm{CI}_{\mathrm{adj}}=1.04-1.39\right.$; $\left.\mathrm{P}_{\mathrm{adj}}=0.013\right)$. Moreover, SNP rs762551 CYP1A2 was associated with the age of manifestation of arterial hypertension (Difference ${ }_{\text {adj }}=1.51 ; 95 \% \mathrm{CI}_{\mathrm{adj}}=0.22-2.80$ ) and cholesterol level (Difference $\mathrm{adj}=-0.15 ; 95 \% \mathrm{Cl}_{\mathrm{adj}}=-0.29--0.01$ ). Conclusion: Thus, in this study, for the first time, there was found the association of rs762551 CYP1A2 and rs1045642 $A B C B 1$ (MDR1) with arterial hypertension in Russians.
\end{abstract}

Keywords: arterial hypertension; cytochrome P450; biotransformation of xenobiotics; rs762551; CYP1A2; rs 1045642; MDR1; $A B C B 1$

Acknowledgements: I would like to expresses my gratitude to my colleagues, Professor V.P. Ivanov, as well as Professor A.V. Polonikov for valuable suggestions in carrying out this research. 
For citation: BushuevaOYu. Single nucleotide polymorphisms in genes encoding xenobiotic metabolizing enzymes are associated with predisposition to arterial hypertension. Research Results in Biomedicine. 2020;6(4):447-456. DOI: 10.18413/2658-65332020-6-4-0-1

Introduction. Arterial hypertension (AH) is the most common disease of the cardiovascular system. More than $30 \%$ of the world's adult population suffer from $\mathrm{AH}$ [1]. From a genetic point of view, $\mathrm{AH}$ is a multifactorial polygenic hereditary disease.

Numerous studies prove that various aerosol polycyclic aromatic hydrocarbons (PAHs) are the main source of organic toxic chemicals with potential effects on the cardiovascular system [2]. PAHs are widely spread in the environment: they are found in cigarette smoke, they are formed during cooking with incomplete combustion of organic materials such as coal and oil products, they are byproducts of various industrial enterprises [3]. Intracellular chemical and oxidative stress, which can be associated both with direct exposure to toxic xenobiotics and with their excessive activation during biotransformation, are the cause of endothelial dysfunction. In particular, it was shown that nitrated and oxidized polyaromatic hydrocarbons can reduce both the activity of endothelial NO synthase (eNOS) and NO production through mechanisms associated with the effect of phosphorylated eNOS on eNOS mRNA expression and eNOS protein expression [4]. Considering the crucial role of $\mathrm{NO}$ in the regulation of vascular tone and endothelial dysfunction [5], it is obvious that variations in genes involved in different stages of biotransformation of xenobiotics can be a risk factor for the development of arterial hypertension through participation in key pathogenetic mechanisms of AH development.

Cytochrome P4501A1 (CYP1A1) is an important member of the CYP family and is responsible for the metabolism of a large number of xenobiotics, as well as some endogenous substrates. In particular, CYP1A1 acts as a major enzyme in the metabolism of PAHs [6]. CYP1A1 is also involved in the production of vasoactive substances based on arachidonic acid - epoxyeicosatrienoic acids
(EETs) and hydroxyeicosatetraenoic acid (HETE), which are endogenous defense mechanisms against cardiovascular disease [7]. Moreover, CYP1A1 is also involved in the oxidative metabolism of estradiol and estrone [8]. The rs1048943 CYPlAl genetic variant is one of the most functionally significant. Substitution of A for $G$ in the 7 th exon of the gene leads to the replacement of Isoleucine with Valine in the structure of the enzyme (Ile462Val). This SNP is located in the heme-binding region of the protein CYP1A1 and can lead to a twofold increase in enzyme activity [9].

CYP1A2 encoded by the CYP1A2 gene, participates in the metabolism of a wide range of xenobiotics, such as heterocyclic aromatic amines and PAHs [10]. CYP1A2 is also an important enzyme, which is responsible for the metabolism of caffeine. CYP1A2 expression is induced by environmental chemicals and is highly variable between individuals [11]. CYP1A2 gene is highly polymorphic. The rs762551 CYP1A2 genetic variant can lead to a 2-3-fold increase in protein activity [12].

CYP1B1 - cytochrome P450 product oxidizes various compounds such as steroids (17-beta-estradiol), fatty acids, retinoids and xenobiotics including PAHs. In blood vessels, $C Y P 1 B 1$ is expressed predominantly in vascular smooth muscle cells, to a lesser extent - in endothelial cells [13]. In animal experiments, it was shown that the endothelial dysfunction observed in angiotensin II-induced hypertension in mice was prevented by silencing the CYP1B1 gene [14]. The most studied rs1056836 genetic variant in the CYP1B1 gene leads to the replacement of Leucine with Valine at the 432 position of the encoded protein [15].

NAT2 is a phase II xenobiotic biotransformation enzyme which carries out conjugation of exogenous arylamine-containing substances, components of some drugs, caffeine [16]. The gene encoding cytosolic 
$\mathrm{N}$-acetyltransferase is located on chromosome $8 \mathrm{p} 22$. Variations in the NAT2 gene lead to a change in the level of functional activity of isoniazid acetylation, which has been classified as fast, intermediate, and slow [17]. Amino acid replacement 590G $>$ A (Arg $>$ Gln; rs1799930) leads to a change in the functional activity of the enzyme. Slow acetylation phenotype associated with the AA NAT2 genotype is unable to conjugate to metabolites or toxins; GA heterozygotes have intermediate enzyme activity.

$\mathrm{NAD}(\mathrm{P}) \mathrm{H}$ quinone oxidoreductase 1 (NQO1) - an enzyme of phase II of biotransformation of xenobiotics - catalyses the reduction of various quinones using NAD $(\mathrm{P}) \mathrm{H}$ as an electron donor. The transformation of quinones to hydroquinones using NQO1 represents an important mechanism of cell defence against oxidative and chemical stress [18]. Single-nucleotide polymorphism rs1800566 NQO1 in the 6th exon of the gene leads to the substitution of Proline for Serine in the $187^{\text {th }}$ amino acid. It was shown that the 187SS variant genotype causes a complete loss of the enzymatic activity of NQO1, while in heterozygotes 187PS there is an almost threefold decrease in the enzyme activity.

The multidrug resistance gene (MDRI) encodes an integrated transmembrane protein, P-glycoprotein, which plays an important role in the bioavailability of certain drugs, as well as in the protection of cells from toxic substances and metabolites through the action of an ATP-dependent mechanism of "cell outflow" [19]. MDR1 has broad substrate specificity. Of more than 50 single nucleotide polymorphisms of MDR1, the functionally significant C3435T (rs 1045642) is the most widely studied [20].

The aim of the study was to investigate the association between common SNP in genes encoding xenobiotics biotransformation enzymes (rs1048943 CYP1A1, rs762551 CYP1A2, rs1056836 CYP1B1, rs1799930 NAT2, rs1800566 NQO1, rs1045642 MDR1) and the risk of $\mathrm{AH}$.

Materials and methods. A total of 1559 unrelated Russian individuals from the Kursk region were examined; written in- formed consent was obtained from all participants prior to entering the study. This study included 702 patients with diagnosis of arterial hypertension. AH patients were hospitalized in the cardiac units of the Kursk Regional Clinical Hospital and the Kursk City Clinical Emergency Hospital in the period 20112017 [21, 22, 23]. The AH group included patients with systolic blood pressure (SBP) $\geq 140 \mathrm{~mm} \mathrm{Hg}$. and/or diastolic blood pressure (DBP) $\geq 90 \mathrm{~mm} \mathrm{Hg}$, as well as patients who received antihypertensive therapy. Exclusion criteria: symptomatic arterial hypertension, acute inflammatory diseases, autoimmune diseases, severe kidney or liver disease, oncological pathology, pregnancy. Patients with ischemic heart disease, cerebral stroke, diabetes mellitus were also excluded from the study. The control group consisted of 857 gender- and age-matched healthy individuals, without a history of cardiovascular and cerebrovascular diseases and with normal level of blood pressure (Table 1). The control group was formed from relatively healthy volunteers, as well as during professional examinations at industrial enterprises, in medical institutions of Kursk and the Kursk region. The formation of $\mathrm{AH}$ group and control group was carried out using a continuous method.

The study was approved by the Regional Ethics Committee of Kursk State Medical University. All patients signed a voluntary informed consent to participate in the study. Venous blood samples were obtained from all individuals. Genomic DNA was isolated from peripheral blood using the standard phenolchloroform extraction procedure. The main criteria for SNP selection were the functional significance of polymorphism and the frequency of the minor allele over 5\%. Genotyping of rs1048943 CYP1A1, rs762551 CYP1A2, rs1056836 CYP1B1, rs1799930 NAT2, rs1800566 NQO1, rs1045642 MDR1 was performed by TaqMan-based PCR using CFX96 detection system (Bio-Rad, USA). Regenotyping of $10 \%$ of the studied samples, selected on a random basis and in the absence of information about the status of the disease, showed $100 \%$ reproducibility of the original results. 
Table 1

\section{Baseline and clinical characteristics of the studied groups}

\begin{tabular}{|c|c|c|c|c|}
\hline \multicolumn{2}{|c|}{ Baselineandclinicalcharacteristics } & $\begin{array}{c}\text { AH patients } \\
(\mathrm{N}=702)\end{array}$ & $\begin{array}{l}\text { Controls } \\
(\mathrm{N}=857)\end{array}$ & $\mathbf{P}$ \\
\hline \multicolumn{2}{|c|}{ Age. Me [Q1; Q3] } & $55[48 ; 62]$ & $53[49 ; 59]$ & 0.84 \\
\hline \multirow{2}{*}{ Gender } & Male. N(\%) & $307(43.7)$ & $406(47.4)$ & \multirow{2}{*}{$1.92(0.17)$} \\
\hline & Female. N(\%) & $27(45.8)$ & $451(52.6)$ & \\
\hline \multirow{2}{*}{ Smoking } & Yes. N(\%) & $182(29.8 \%)$ & $295(37.8 \%)$ & \multirow{2}{*}{$0.0036 *$} \\
\hline & No. N(\%) & $429(70.2 \%)$ & $486(62.2 \%)$ & \\
\hline \multicolumn{2}{|c|}{ Maximumsystolicbloodpressure } & $230[200 ; 250]$ & - & - \\
\hline \multicolumn{2}{|c|}{ Maximumdiastolicbloodpressure } & $120(115 ; 140)$ & - & - \\
\hline \multicolumn{2}{|c|}{ Total cholesterol. Me [Q1; Q3] } & $4.80[4.20 ; 5.43]$ & - & - \\
\hline \multicolumn{2}{|c|}{ Triglycerides. Me [Q1; Q3] } & $1.985[1.44 ; 2.46]$ & - & - \\
\hline \multicolumn{2}{|c|}{ Glucose level. Me [Q1; Q3] } & $4.58[4.10 ; 5.41]$ & - & - \\
\hline \multicolumn{2}{|c|}{$\begin{array}{c}\text { Age of AH manifestation. } \\
\text { Me [Q1; Q3] }\end{array}$} & $33.5[25.0 ; 44.0]$ & - & - \\
\hline
\end{tabular}

Note: *-shows statistically significant differences between groups.

To assess the associations of genotypes with predisposition to $\mathrm{AH}$, the odds ratio (OR) and 95\% confidence interval (CI), calculated for the log-additive regression model, were used. All calculations were performed with corrections for gender and age in the SNPStats program available online (https://www.snpstats.net/start.htm). To assess the regulatory potential of SNPs, bioinformatic resources available online were used: QTLbase (http://mulinlab.org/qtlbase) and HaploReg v.4 (https://pubs.broadinstitute.org/mammals/hapl oreg/haploreg.php).

Results and discussion. The analysis of Hardy-Weinberg equilibrium was carried out in the control group. The distribution of genotype frequencies for all studied SNPs, except for rs762551 CYP1A2, corresponded to the Hardy-Weinberg equilibrium ( $\mathrm{P}>0.05$ ). For rs762551 CYP1A2, we revealed a decrease in observed heterozygosity (0.40) versus expected (0.45); P <0.01.

SNP rs762551 CYP1A2 was associated with a decreased risk of $\mathrm{AH}(\mathrm{OR}=0.85,95 \%$ $\mathrm{CI}=0.73-0.99, \quad \mathrm{P}=0.038) . \quad \mathrm{SNP} \quad \mathrm{rs} 1045642$ $A B C B 1$ was associated with an increased risk of $\mathrm{AH} \quad(\mathrm{OR}=1.20, \quad 95 \% \quad \mathrm{CI}=1.04-1.39$, $\mathrm{P}=0.013$ ) (Table 2).

Subsequent analysis of the relationship of the studied genetic variants with clinical and laboratory parameters in patients with $\mathrm{AH}$ revealed an association of rs762551 CYP1A2 with the age of manifestation of $\mathrm{AH}$ and cholesterol level: carriers of the $\mathrm{C} / \mathrm{C}$ genotype had the lowest cholesterol levels and the latest manifestation of hypertension (Table 3). It should also be noted that SNP rs1799930 NAT2 was associated with blood glucose levels.

Our study revealed an association of rs762551 CYP1A2 with the decreased risk of $\mathrm{AH}$. This association was discovered for the first time in the population of Central Russia. It is important that rs762551 CYP1A2 was associated with age at onset of $\mathrm{AH}$ and cholesterol levels. The CYP1A2 gene encodes a member of the cytochrome P450 superfamily of enzymes. Cytochrome $\mathrm{P} 450$ proteins are monooxygenases that catalyse reactions involved in the metabolism of xenobiotics and the synthesis of sex steroids, cholesterol, and other lipids. The protein encoded by this gene is localized in the endoplasmic reticulum, and its expression is induced by polycyclic aromatic hydrocarbons (PAHs), some of which are found in components of cigarette smoke. The endogenous substrate of the enzyme is unknown; however, it is able to metabolize some PAHs to intermediates (https://www.genecards.org/cgibin/carddisp.pl?gene=CYP1A2). 
Table 2

Analysis of associations of SNP in genes encoding xenobiotic biotransformation enzymes with the development of arterial hypertension

\begin{tabular}{|c|c|c|c|c|c|c|}
\hline \multirow[b]{2}{*}{ № } & \multirow[b]{2}{*}{ SNP } & \multirow[b]{2}{*}{ Genotypes } & \multicolumn{2}{|c|}{$\mathrm{N}(\%)^{1}$} & \multirow{2}{*}{$\begin{array}{c}{ }_{\text {cor OR }} \\
(95 \% \mathrm{CI})^{2}\end{array}$} & \multirow[b]{2}{*}{${ }_{\operatorname{cor}} \mathbf{P}^{3}$} \\
\hline & & & $\begin{array}{c}\text { Controls } \\
(\mathrm{n}=857)\end{array}$ & $\begin{array}{r}\text { Patients } \\
(n=702)\end{array}$ & & \\
\hline \multirow{3}{*}{1.} & \multirow{3}{*}{$\begin{array}{c}\text { rs1048943 } \\
\text { CYP1A1 }\end{array}$} & $\mathrm{I} / \mathrm{I}$ & $643(85.2 \%)$ & $548(86.2 \%)$ & \multirow{3}{*}{$\begin{array}{c}0.91 \\
(0.69-1.22)\end{array}$} & \multirow{3}{*}{0.54} \\
\hline & & $\mathrm{I} / \mathrm{V}$ & $108(14.3 \%)$ & $84(13.2 \%)$ & & \\
\hline & & $\mathrm{V} / \mathrm{V}$ & $4(0.5 \%)$ & $4(0.6 \%)$ & & \\
\hline \multirow{3}{*}{2.} & \multirow{3}{*}{$\begin{array}{c}\text { rs762551 } \\
C Y P 1 A 2\end{array}$} & $\mathrm{~A} / \mathrm{A}$ & $372(46.6 \%)$ & $311(51 \%)$ & \multirow{3}{*}{$\begin{array}{c}0.85 \\
(0.73-0.99)\end{array}$} & \multirow{3}{*}{0.038} \\
\hline & & $\mathrm{A} / \mathrm{C}$ & $318(39.9 \%)$ & $238(39 \%)$ & & \\
\hline & & $\mathrm{C} / \mathrm{C}$ & $108(13.5 \%)$ & $61(10 \%)$ & & \\
\hline \multirow{3}{*}{3.} & \multirow{3}{*}{$\begin{array}{c}\text { rs1056836 } \\
C Y P 1 B 1\end{array}$} & $\mathrm{~L} / \mathrm{L}$ & $270(32.9 \%)$ & $199(31.4 \%)$ & \multirow{3}{*}{$\begin{array}{c}1.05 \\
(0.91-1.22)\end{array}$} & \multirow{3}{*}{0.5} \\
\hline & & $\mathrm{L} / \mathrm{V}$ & $397(48.4 \%)$ & $313(49.4 \%)$ & & \\
\hline & & $\mathrm{V} / \mathrm{V}$ & $154(18.8 \%)$ & $122(19.2 \%)$ & & \\
\hline \multirow{3}{*}{4.} & \multirow{3}{*}{$\begin{array}{c}\text { rs } 1799930 \\
\text { NAT2 }\end{array}$} & $\mathrm{G} / \mathrm{G}$ & $386(49 \%)$ & $309(48.4 \%)$ & \multirow{3}{*}{$\begin{array}{c}0.98 \\
(0.83-1.15)\end{array}$} & \multirow{3}{*}{0.79} \\
\hline & & G/A & $329(41.8 \%)$ & $278(43.6 \%)$ & & \\
\hline & & $\mathrm{A} / \mathrm{A}$ & $73(9.3 \%)$ & $51(8 \%)$ & & \\
\hline \multirow{3}{*}{5.} & \multirow{3}{*}{$\begin{array}{c}\text { rs } 1800566 \\
N Q O 1\end{array}$} & $\mathrm{P} / \mathrm{P}$ & $485(63.1 \%)$ & $392(62.5 \%)$ & \multirow{3}{*}{$\begin{array}{c}0.98 \\
(0.82-1.17)\end{array}$} & \multirow{3}{*}{0.82} \\
\hline & & $\mathrm{P} / \mathrm{S}$ & $239(31.1 \%)$ & $206(32.9 \%)$ & & \\
\hline & & $\mathrm{S} / \mathrm{S}$ & $45(5.8 \%)$ & $29(4.6 \%)$ & & \\
\hline \multirow{3}{*}{6.} & \multirow{3}{*}{$\begin{array}{c}\mathrm{rs} 1045642 \\
A B C B 1\end{array}$} & $\mathrm{C} / \mathrm{C}$ & $273(33.4 \%)$ & $180(28.4 \%)$ & \multirow{3}{*}{$\begin{array}{c}1.20 \\
(1.04-1.39)\end{array}$} & \multirow{3}{*}{0.013} \\
\hline & & $\mathrm{C} / \mathrm{T}$ & $384(47 \%)$ & $306(48.3 \%)$ & & \\
\hline & & $\mathrm{T} / \mathrm{T}$ & $160(19.6 \%)$ & $147(23.2 \%)$ & & \\
\hline
\end{tabular}

Note: all calculations are performed with respect to the minor allele; statistically significant associations are marked in bold; 1 - the absolute number and \% of individuals with the analyzed genotype; 2 - odds ratio and $95 \%$ confidence interval (calculated for the log-additive regression model) corrected for gender and age; 3 - P-value for log-additive regression model with correction for sex and age.

Table 3

\section{Statistically significant associations of studied genetic variants with clinical and laboratory parameters of hypertensive patients}

\begin{tabular}{|c|c|c|c|c|c|}
\hline Phenotype & Gene/SNP & Genotypes & $\operatorname{Mean} \pm$ StD $^{1}$ & $\begin{array}{c}\text { adjDifference } \\
(95 \% \mathrm{Cl})^{2}\end{array}$ & ${ }_{\text {adj }} \mathbf{P}^{3}$ \\
\hline \multirow{3}{*}{$\begin{array}{l}\text { Age of manifestation of } \\
\text { AH }\end{array}$} & \multirow{3}{*}{$\begin{array}{c}\text { CYP1A2 } \\
(\mathrm{rs} 762551)\end{array}$} & $\mathrm{A} / \mathrm{A}$ & $41.96(1.95)$ & \multirow{3}{*}{$\begin{array}{c}1.51 \\
(0.22-2.80)\end{array}$} & \multirow{3}{*}{$\mathbf{0 . 0 2 3}$} \\
\hline & & $\mathrm{A} / \mathrm{C}$ & $44.12(1)$ & & \\
\hline & & $\mathrm{C} / \mathrm{C}$ & $44.91(0.88)$ & & \\
\hline \multirow{3}{*}{$\begin{array}{l}\text { Cholesterol } \\
\text { level }\end{array}$} & \multirow{3}{*}{$\begin{array}{c}C Y P 1 A 2 \\
(\mathrm{rs} 762551)\end{array}$} & $\mathrm{A} / \mathrm{A}$ & $5.31(0.07)$ & \multirow{3}{*}{$\begin{array}{c}-0.15 \\
(-0.29--0.01)\end{array}$} & \multirow{3}{*}{0.032} \\
\hline & & $\mathrm{A} / \mathrm{C}$ & $5.14(0.08)$ & & \\
\hline & & $\mathrm{C} / \mathrm{C}$ & $4.99(0.15)$ & & \\
\hline \multirow[t]{3}{*}{ Blood glucose levels } & \multirow{3}{*}{$\begin{array}{c}N A T 2 \\
(\mathrm{rs} 1799930)\end{array}$} & $\mathrm{G} / \mathrm{G}$ & $5.43(0.12)$ & \multirow{3}{*}{$\begin{array}{c}-0.24 \\
(-0.47--0.01)\end{array}$} & \multirow{3}{*}{0.046} \\
\hline & & $\mathrm{G} / \mathrm{A}$ & $5.26(0.11)$ & & \\
\hline & & $\mathrm{A} / \mathrm{A}$ & $4.94(0.13)$ & & \\
\hline
\end{tabular}

Note: the results of the log-additive model are presented. All calculations were performed with a correction for the sex and age (adj); 1 - Mean \pm StD - an indicator of the mean and standard deviation; 2 - the difference in mean values (measures the absolute difference between the mean in two groups) and 95\% confidence interval; 3 - P-value for the regression model. 
Previous studies have already shown an association of rs762551 polymorphism with blood pressure variability and hypertension [24].It is known that the studied rs762551 CYP1A2 is in linkage disequilibrium with the SNP rs1378942 (HapMap CEU), which is located in the CYPIA2 gene cluster and showed the strongest association with diastolic blood pressure in Europeans [25]. Moreover, an association between rs762551 and the risk of AH was shown in the study by GuessousI, et al [26], who noted a negative association of rs762551 with hypertension in non-smokers, modified by caffeine intake. The previous studies of $C Y P 1 A 2$ in mice have demonstrated an important role for this enzyme in oxidative stress [27] and in lipid metabolism [28], which could explain the effect of the rs762551 CYP1A2 on cholesterol levels found in our study. It was shown that CYPIA2 -/mice were characterized by a change in the expression of genes involved in the pathways of cholesterol biosynthesis and fatty acid metabolism. Moreover, in patients with cardiovascular diseases, which were characterized by low CYP1A2 activity, there was an increased level of inflammatory cytokines that may be involved in the pathogenesis of cardiovascular diseases [29]. These observations indicate that low CYP1A2 levels have adverse biological effects that may explain not only the increased risk of $\mathrm{AH}$, but also impaired cholesterol metabolism.

Bioinformatics analysis was performed to explain the functional effects of rs762551 CYP1A2. According to the QTLbase, the carriage of the protective $\mathrm{C}$ allele is associated with 17 cis-mQTLs associated with a decrease in methylation of $\mathrm{CpG}$ sites in CYP1A2 (Table 4). Because a decrease in methylation can lead to an increase in gene expression, the protective effects of the $C$ allele can also be mediated by cis-mQTL. At the same time, for the risk allele A, 2 cis-hQTLs were found associated with a decrease in acetylation at the 27th lysine residue on the histone $\mathrm{H} 3$ protein in $\mathrm{CD} 14+$ monocytes and CD16+ neutrophils in peripheral blood and, therefore, with a potential decrease in CYP1A2 expression (Table 4).

\section{Cis-mQTL/cis-hQTL, associated withrs762551 CYP1A2}

\begin{tabular}{|c|c|c|c|c|}
\hline № & CpGsite (genomicregion) & Effect size (beta) & P-level & Tissue \\
\hline \multicolumn{5}{|c|}{ Cis-mQTL associated with a decrease in methylation of CpG-sites in carriers of the protective allele C rs762551 CYP1A2 } \\
\hline 1. & $\operatorname{cg} 20927731(\mathrm{chr} 15: 74726561)$ & -0.029 & 0.0194 & blood \\
\hline 2. & $\operatorname{cg} 18176723(\operatorname{chr} 15: 75336436)$ & -0.069 & $6.25 \times 10^{-6}$ & blood \\
\hline 3. & $\operatorname{cg} 13055199(\operatorname{chr} 15: 75136278)$ & -0.119 & $3.07 \times 10^{-11}$ & blood \\
\hline 4. & $\operatorname{cg} 20801110(\operatorname{chr} 15: 75136007)$ & -0.029 & 0.0146 & blood \\
\hline 5. & $\operatorname{cg} 06285340(\operatorname{chr} 15: 74659901)$ & -0.018 & 0.0157 & blood \\
\hline 6. & $\operatorname{cg} 03289416(\operatorname{chr} 15: 75166202)$ & -0.053 & 0.00013 & blood \\
\hline 7. & $\operatorname{cg} 02696790(\operatorname{chr} 15: 75250997)$ & -0.038 & 0.000154 & blood \\
\hline 8. & cg20997706 (chr15:74907203) & -0.027 & 0.0147 & blood \\
\hline 9. & $\operatorname{cg} 27140083(\operatorname{chr} 15: 75230280)$ & -0.034 & 0.00241 & blood \\
\hline 10. & $\operatorname{cg} 13316255(\operatorname{chr} 15: 75165642)$ & -0.026 & 0.0253 & blood \\
\hline 11. & $\operatorname{cg} 00629941(\operatorname{chr} 15: 75287862)$ & 0.025 & 0.0335 & blood \\
\hline 12. & $\operatorname{cg} 20552236(\operatorname{chr} 15: 75090958)$ & -0.024 & 0.00637 & blood \\
\hline 13. & $\operatorname{cg} 04629595(\operatorname{chr} 15: 74592566)$ & -0.034 & 0.0195 & blood \\
\hline 14. & cg21565421 (chr15:74592665) & -0.03 & 0.0192 & blood \\
\hline 15. & $\operatorname{cg} 04877966(\mathrm{chr} 15: 75135169)$ & -0.024 & 0.00138 & blood \\
\hline 16. & $\operatorname{cg} 00516515(\mathrm{chr} 15: 75091516)$ & -0.028 & 0.00257 & blood \\
\hline 17. & $\operatorname{cg} 10785927(\operatorname{chr} 15: 74753902)$ & -0.016 & 0.023 & blood \\
\hline \multicolumn{5}{|c|}{ Association of cis-hQTL with histone modifications in carriers of the risk allele A of rs762551 CYP1A2 } \\
\hline № & Modifiedhistone & $\begin{array}{l}\text { Effect size (be- } \\
\text { ta) }\end{array}$ & P-level & Tissue \\
\hline 1. & $\begin{array}{c}\text { H3K27ac } \\
(\operatorname{chr} 15: 74900758-74937630)\end{array}$ & -0.08676 & 0.0145 & $\begin{array}{c}\text { Blood } \\
\text { (monocytes CD14+) }\end{array}$ \\
\hline 2. & $\begin{array}{c}\text { H3K27ac } \\
(\operatorname{chr} 15: 75000467-75006123)\end{array}$ & -0.0937 & 0.0373 & $\begin{array}{c}\text { Blood } \\
\text { (neutrophils CD16+) }\end{array}$ \\
\hline
\end{tabular}

Note: the data is provided by the QTLbase resource (http://mulinlab.org/qtlbase). 
According to the HaploReg database (v4.1), this polymorphism is associated with trans-eQTLs for the $U L K 3$ gene in visceral and subcutaneous adipose tissue, pancreas, whole blood (ULK3 encodes serine/threonine kinase protein, which acts as a regulator of autophagy); for the CSK gene in whole blood (tyrosine protein kinase CSK; non-receptor tyrosine protein kinases, which play an important role in the regulation of cell growth, differentiation, migration, immune response) (https://pubs.broadinstitute.org/mammals/hapl oreg/detail_v4.1.php ? query $=\&$ id $=$ rs762551). Therefore, rs762551-trans-eQTLs may be associated with the development of $\mathrm{AH}$ through mechanisms involved in the regulation of growth, differentiation, cell migration, and autophagy processes.

Thus, the present study provided additional evidence that $C Y P 1 A 2$ is an important gene for cardiovascular diseases susceptibility.

Another gene involved in xenobiotics biotransformation and associated with $\mathrm{AH}$ was MDRI (multidrug resistance gene). It was found that the genetic variant $3435 \mathrm{C}>\mathrm{T}$ (rs1045642) ABCB1 (MDRl) was associated with an increased risk of $\mathrm{AH}$. P-glycoprotein, a protein from the ABCB-transporter family, is involved in the active transport of xenobiotics from the intracellular to the extracellular space [30]. This trans-membrane protein is expressed in numerous tissues, including the vascular endothelial cells. P-glycoprotein is encoded by the $A B C B 1$ gene. The $A B C B 1$ gene is located on the long arm of chromosome 7 and consists of 29 exons (https://www.ncbi.nlm.nih.gov/gene/5243).

Many single nucleotide polymorphisms have been found in this gene; however, the most studied genetic variant is rs 1045642 .Variation of C3435T in exon 26 does not lead to an amino acid substitution, however, it affects gene expression, in particular, it reduces the stability of mRNA and, as a consequence, the activity of the transmembrane P-glycoprotein [31]. In a study of the Chinese Han population, rs $1045642 A B C B 1$ has been shown to be associated with blood pressure [32]. It was also found that this SNP is associated with an increased risk of $\mathrm{AH}$ in patients with chronic kidney disease [33].
The association of $\mathrm{C} 3435 \mathrm{~T} A B C B 1$ with $\mathrm{AH}$ can be explained by three mechanisms. Firstly, it is known that P-glycoprotein is involved in the secretion of aldosterone in the adrenal glomerular zone [34]. Secondly, animal studies have shown that P-glycoprotein is involved in the transport of oxidized glutathione and thus is associated with oxidative stress - one of the main triggers of AH [35]. Thirdly, P-glycoprotein significantly affects endothelium-dependent vasodilation, reducing NO synthesis [36].

Protective allele $\mathrm{C}$ rs1045642 $A B C B 1$ may be associatedwith the increased gene expression in blood cells by cis-eQTL-mediated mechanisms (Table 5).

According to HaploReg resource data (v4.1), rs1045642 $A B C B 1$ is located in the region of DNA binding with modified histone $\mathrm{H} 3 \mathrm{~K} 27 \mathrm{ac}$ marking enhancers (in peripheral blood cells), with modified histone H3K9ac marking promoters (in primary mononuclear cells of peripheral blood).

$\mathrm{N}$-acetyltransferase 2 (NAT2) is phase II xenobiotics biotransformation enzyme which plays an important role in both detoxification and activation of many xenobiotics [16]. Diabetes mellitus (DM) is one of the diseases whose association has been studied in relation to acetylation phenotypes. Previous studies have already shown a positive association between air pollutants and insulin resistance in subjects with the GG genotype of the rapid acetylator phenotype rs1799930 NAT2 [37]. Another study also showed that T2DM patients with the rapid acetylator phenotype (carriers of the GG genotype) had significantly higher absolute insulin levels and lower insulin sensitivity compared with patients characterized by a slow acetylator phenotype [38].

Thus, despite the fact that there were no patients with diabetes mellitus among patients with $\mathrm{AH}$, it can be assumed that the genetically determined type of acetylator by the single nucleotide polymorphism rs1799930 NAT2 can modify the complex of quantitative phenotypic manifestations associated with the risk of type 2 diabetes mellitus. 
Cis-eQTL/cis-hQTL, associated withrs1045642 ABCB1 (MDRI)

\begin{tabular}{|l|c|c|c|c|}
\hline \multicolumn{1}{|c|}{ No } & Trait & $\begin{array}{c}\text { Effect size } \\
\text { (beta) }\end{array}$ & P-level & Tissue \\
\hline \multicolumn{2}{|c|}{ Association of cis-eQTL with level of $A B C B 1$ expression in carriers of the protective C allele rs1045642 $A B C B 1$} \\
\hline 1. & ABCB1 & NA & $3.0 \times 10^{-7}$ & Peripheralblood \\
\hline 2. & ABCB1 & 1.855966 & 0.0635 & Blood (B-cells) \\
\hline 3. & ABCB1 & 2.20673 & 0.0273 & Blood (monocytes) \\
\hline \multicolumn{4}{|c|}{ Association of cis-hQTL with histone modifications in carriers of the protective C allele rs1045642 $A B C B 1$} \\
\hline 4. & H3K4me1 & 0.07597 & 0.0496 & Blood \\
& (chr7:87101300-87108186) & & & (T-cells CD4+) \\
\hline
\end{tabular}

Note: the data is provided by the QTLbase resource (http://mulinlab.org/qtlbase).

Conclusion. Thus, in this study, for the first time, the association of rs762551 $C Y P 1 A 2$ and rs1045642 ABCB1 (MDRI) with $\mathrm{AH}$ in the Russians was found, which provides additional evidence for the role of «chemical stress» in the pathogenesis of cardiovascular pathology. It is also worth noting that bioinformatics analysis revealed a high regulatory potential of rs762551 and rs1045642, suggesting a potentially important role of epigenetic mechanisms in the regulation of gene expression. From a practical point of view, the results obtained can be used to develop new approaches to the prevention and treatment of cardiovascular diseases, based on the "fight" against toxic xenobiotics of the environment.

\section{Financial support}

The study was carried out with financial support from Kursk State Medical University.

\section{Conflict of interests}

The author has no conflict of interest to declare.

\section{References}

1. Mills KT, Bundy JD, Kelly TN, et al. Global Disparities of Hypertension Prevalence and Control: A Systematic Analysis of Population-Based Studies From 90 Countries. Circulation. 2016;134(6):441-450. DOI: https://doi.org/10.1161/CIRCULATIONAHA.115 .018912

2. Holme JA, Brinchmann BC, Refsnes $\mathrm{M}$, et al. Potential role of polycyclic aromatic hydrocarbons as mediators of cardiovascular effects from combustion particles. EnvironmentalHealth. 2019;18(1):74.

DOI:https://doi.org/10.1186/s12940-019-0514-2
3. Manisalidis I, Stavropoulou E, Stavropoulos A, et al. Environmental and Health Impacts of Air Pollution: A Review. Frontiers in Public Health. 2020;8:14. DOI: https://doi.org/10.3389/fpubh.2020.00014

4. $\mathrm{Wu} \mathrm{H}, \mathrm{Lu} \mathrm{L}$, Chen J, et al. Inhibited Nitric Oxide Production of Human Endothelial Nitric Oxide Synthase by Nitrated and Oxygenated Polycyclic Aromatic Hydrocarbons. Environmental Science \& Technology. 2020;54(5):29222930.

DOI: https://doi.org/10.1021/acs.est.9b07163

5. Gheibi S, Jeddi S, Kashfi K, et al. Regulation of vascular tone homeostasis by NO and $\mathrm{H}_{2} \mathrm{~S}$ : Implications in hypertension. Biochemical Pharmacology. 2018;149:42-59. DOI: https://doi.org/10.1016/j.bcp.2018.01.017

6. Mescher M, Haarmann-Stemmann T. Modulation of CYP1A1 metabolism: From adverse health effects to chemoprevention and therapeutic options. Pharmacology and Therapeutics. 2018;187:71-87.

DOI: https://doi.org/10.1016/j.pharmthera.2018.02.012

7. Hankinson $\mathrm{O}$. The role of AHRinducible cytochrome P450s in metabolism of polyunsaturated fatty acids. Drug Metabolism Reviews. 2016;48(3):342-350. DOI: https://doi.org/10.1080/03602532.2016.1197240

8. Tarnow P, Tralau T, Luch A. Chemical activation of estrogen and aryl hydrocarbon receptor signaling pathways and their interaction in toxicology and metabolism. Expert Opinion on Drug Metabolism and Toxicology. 2019;15(3):219-229. DOI:

https://doi.org/10.1080/17425255.2019.1569627

9. Gastelum G, Jiang W, Wang L, et al. Polycyclic Aromatic Hydrocarbon (PAH)-Induced Pulmonary Carcinogenesis in Cytochrome P450 (CYP) 1A1- and 1A2-null Mice: Roles of CYP1A1 and CYP1A2. Toxicological Sciences. 2020;177(2):347-361.

DOI: 
10. Chen Y, Zeng L, Wang Y, et al. The expression, induction and pharmacological activity of CYP1A2 are post-transcriptionally regulated by microRNA hsa-miR-1325p. BiochemicalPharmacology. 2017;145:178191.

DOI: https://doi.org/10.1016/j.bcp.2017.08.012

11. Ibrahim M, MacFarlane EM, Matteo $\mathrm{G}$, et al. Functional cytochrome P450 1A enzymes are induced in mouse and human islets following pollutant exposure. Diabetologia. 2020;63(1):162178. DOI: https://doi.org/10.1007/s00125-01905035-0

12. Koonrungsesomboon N, Khatsri R, Wongchompoo $\mathrm{P}$, et al. The impact of genetic polymorphisms on CYP1A2 activity in humans: a systematic review and meta-analysis. Pharmacogenomics Journal. 2018;18(6):760-768. DOI: https://doi.org/10.1038/s41397-017-0011-3

13. Falero-Perez J, Song YS, Sorenson CM, Sheibani N. CYP1B1: A key regulator of redox homeostasis. Trends in Cell Biology. 2018;13:27-45.

14. Jennings BL, Sahan-Firat S, Estes AM, et al. Cytochrome P450 1B1 contributes to angiotensin II-induced hypertension and associated pathophysiology. Hypertension. 2010;56(4):667674. DOI: https://doi.org/10.1161/HYPERTENSIONAHA.1 10.154518

15. Docea AO, Vassilopoulou L, Fragou $\mathrm{D}$, et al. CYP polymorphisms and pathological conditions related to chronic exposure to organochlorine pesticides. Toxicology Reports. 2017;4:335-341. DOI: https://doi.org/10.1016/j.toxrep.2017.05.007

16. Conway LP, Rendo V, Correia MSP, et al. Unexpected Acetylation of Endogenous Aliphatic Amines by Arylamine N-Acetyltransferase NAT2. AngewandteChemie - International Edition. 2020;59(34):14342-14346. DOI: https://doi.org/10.1002/anie.202005915

17. Mitchell SC. N-acetyltransferase: the practical consequences of polymorphic activity in man. Xenobiotica. 2020;50(1):77-91. DOI: https://doi.org/10.1080/00498254.2019.1618511

18. Ross D, Siegel D. NQO1 in protection against oxidative stress. Current Opinion in Toxicology. 2018;7:67-72.

DOI: https://doi.org/10.1016/j.cotox.2017.10.005

19. Guéniche N, Bruyere A, Le Vée M, et al. Implication of human drug transporters to toxicokinetics and toxicity of pesticides. Pest Man- agement Science. 2020;76(1):18-25. DOI: https://doi.org/10.1002/ps.5577

20. Wang L, Yang L, Zhang J, et al. Association of ABCB1 C3435T Polymorphism with Echocardiographic Index Among Patients with Atherosclerotic Ischemic Stroke and Transient Ischemic Attack. Journal of Molecular Neuroscience. 2020;70(9):1445-1450. DOI: https://doi.org/10.1007/s12031-020-01567-y

21. Bushueva OY, Ivanov VP, Ryzhaeva $\mathrm{VN}$, et al. Association of the $-844 \mathrm{G}>\mathrm{A}$ polymorphism in the catalase gene with the increased risk of essential hypertension in smokers. TerapevticheskiiArkhiv. 2016;88(9):50-54. Russian. DOI: https://doi.org/10.17116/terarkh201688950-54

22. Polonikov AV, Bushueva OY, Bulgakova IV, et al. A comprehensive contribution of genes for aryl hydrocarbon receptor signaling pathway to hypertension susceptibility. PharmacogeneticsandGenomics. 2017;27(2):5769.

DOI: https://doi.org/10.1097/FPC.0000000000000261

23. Polonikov A, Bykanova M, Ponomarenko I, et al. The contribution of CYP2C gene subfamily involved in epoxygenase pathway of arachidonic acids metabolism to hypertension susceptibility in Russian population. ClinicalandExperimentalHypertension.

2017;39(4):306-311.

DOI: https://doi.org/10.1080/10641963.2016.1246562

24. Palatini P, Ceolotto G, Ragazzo F, et al. CYP1A2 genotype modifies the association between coffee intake and the risk of hypertension. Journal of Hypertension. 2009;27(8):15941601.

DOI: https://doi.org/10.1097/HJH.0b013e32832ba850

25. Newton-Cheh C, Johnson T, Gateva V, et al. Genome-wide association study identifies eight loci associated with blood pressure. Nature Genetics. 2009;41(6):666-676. DOI: https://doi.org/10.1038/ng.361

26. Guessous I, Dobrinas M, Kutalik Z, et al. Caffeine intake and CYP1A2 variants associated with high caffeine intake protect non-smokers from hypertension. HumanMolecularGenetics. 2012;21(14):3283-3292.

DOI: https://doi.org/10.1093/hmg/dds137

27. Veith A, Moorthy B. Role of cytochrome P450s in the generation and metabolism of reactive oxygen species. Current Opinion in Toxicology. 2018;7:44-51. DOI: https://doi.org/10.1016/j.cotox.2017.10.003

28. Smith AG, Davies R, Dalton TP, et al. Intrinsic hepatic phenotype associated with the 
Cyp1a2 gene as shown by cDNA expression microarray analysis of the knockout mouse. EHP toxicogenomics : journal of the National Institute of Environmental Health Sciences. 2003;111(1T):45-51.

29. Frye RF, Schneider VM, Frye CS, et al. Plasma levels of TNF-alpha and IL-6 are inversely related to cytochrome P450-dependent drug metabolism in patients with congestive heart failure. JournalofCardiacFailure. 2002;8(5):315319.

DOI: https://doi.org/10.1054/jcaf.2002.127773

30. Efferth T, Volm M. Multiple resistance to carcinogens and xenobiotics: P-glycoproteins as universal detoxifiers. Archives of Toxicology. 2017;91(7):2515-2538.

DOI: https://doi.org/10.1007/s00204-017-1938-5

31. Wang D, Johnson AD, Papp AC, et al. Multidrug resistance polypeptide 1 (MDR1, $\mathrm{ABCB} 1$ ) variant $3435 \mathrm{C}>\mathrm{T}$ affects mRNA stability. Pharmacogenetics and Genomics. 2005;15(10):693-704. DOI: https://doi.org/10.1097/01.fpc.0000178311.02878. 83

32. Zhang XW, Yang JL, Liang W, et al. Genetic association study of ABCB1 gene polymorphisms with hypertension in Han Chinese population. EuropeanReviewforMedicalandPharmacologicalSciences. 2016;20(17):3661-3671.

33. Liu M, Li Y, Citterio L, et al. A functional common polymorphism of the ABCB1 gene is associated with chronic kidney disease and hypertension in Chinese. American Journal of Hypertension. 2013;26(12):1428-1436. DOI: https://doi.org/10.1093/ajh/hpt126

34. Bello-Reuss E, Ernest S, Holland OB, et al. Role of multidrug resistance P-glycoprotein in the secretion of aldosterone by human adrenal NCI-H295 cells. American Journal of Physiology - Cell Physiology. 2000;278(6):C1256-C1265. DOI:

https://doi.org/10.1152/ajpcell.2000.278.6.C1256
35. Sita G, Hrelia P, Tarozzi A, et al. Pglycoprotein $(\mathrm{ABCB} 1)$ and Oxidative Stress: Focus on Alzheimer's Disease. Oxidative Medicine and Cellular Longevity. 2017;2017:7905486. DOI: https://doi.org/10.1155/2017/7905486

36. Widder JD, Guzik TJ, Mueller CF, et al. Role of the multidrug resistance protein-1 in hypertension and vascular dysfunction caused by angiotensin II. Arteriosclerosis, Thrombosis, and Vascular Biology. 2007;27(4):762-768. DOI: https://doi.org/10.1161/01.ATV.0000259298.1112 9.a2

37. Kim J.H., Hong Y.C. The effect of exposure to air pollutants on insulin resistance modified by genotypes of GSTM1 and NAT2 in the Korean elderly environmental panel study (KEEPS). ISEE Conference Abstracts. 2011;1. DOI: https://doi.org/10.1289/isee.2011.00985

38. Paul S, Ahmed S, Khan I, et al. Type 2 diabetes mellitus (T2DM) subjects of Bangladeshi origin with fast $\mathrm{N}$-acetyltransferase 2 (NAT2) acetylator phenotype show lower insulin sensitivity than slow acetylator phenotype. International Journal of Diabetes in Developing Countries. 2013;33:213-218. DOI:

https://doi.org/10.1007/s13410-013-0144-0

Received 29 August 2020

Revised 23 October 2020

Accepted 27 October 2020

\section{Information about the authors}

Olga Yu. Bushueva, MD, Cand. Sci. (Medicine), Associate Professor at the Department of Biology, Medical Genetics and Ecology, Head of the Laboratory of Genomic Research, Research Institute for Genetic and Molecular Epidemiology, Kursk State Medical University, Kursk, Russia, E-mail: olga.bushueva@inbox.ru, ORCID: 0000-00033333-0623. 